\title{
Single-cell metabolomics by mass spectrometry: Advances, challenges, and future applications
}

\author{
Ahmed Ali a, b,1, Yasmine Abouleila a, b,1, Yoshihiro Shimizu a, c, Eiso Hiyama ${ }^{\mathrm{d}}$, \\ Samy Emara ${ }^{e}$, Alireza Mashaghi ${ }^{\mathrm{f}, *, 2}$, Thomas Hankemeier ${ }^{\mathrm{f}, * *, 2}$ \\ a Laboratory for Single Cell Mass Spectrometry, RIKEN Center for Biosystems Dynamics Research (BDR), 6-2-3, Furuedai, Suita, Osaka 565-0874, Japan \\ ${ }^{\mathrm{b}}$ Research Center, Misr International University, Cairo, Egypt \\ c Laboratory for Cell-Free Protein Synthesis, RIKEN Center for Biosystems Dynamics Research (BDR), 6-2-3, Furuedai, Suita, Osaka 565-0874, Japan \\ ${ }^{\mathrm{d}}$ Natural Science for Basic Research and Development, Hiroshima University, 1-2-3, Kasumi, Minami, Hiroshima 734-8551, Japan \\ e Faculty of Pharmacy, Misr International University (MIU), Cairo, Egypt \\ f Systems Biomedicine and Pharmacology Division, Leiden Academic Centre for Drug Research (LACDR), Leiden University, Einsteinweg 55, 2333 CC Leiden, \\ the Netherlands
}

\section{A R T I C L E I N F O}

Article history:

Available online 12 March 2019

\section{Keywords:}

Single-cell analysis

Mass spectrometry

Metabolomics

Single-cell isolation

Cellular heterogeneity

\begin{abstract}
A B S T R A C T
Cellular heterogeneity is a phenomenon that is often observed but poorly understood. Single-cell metabolomics can provide insights into the phenotypical variations between individual cells. Recent advances in microfluidics, micromanipulation, image analysis, and automation allowed for highthroughput isolation of single cells in a minimally disruptive manner as to not affect the cell metabolism. Coupled with new innovations in mass spectrometry-based analytical techniques, single cell metabolomics stands at the cusp of becoming an established field. In this review, some of the recent single cell isolation platforms that are especially suited for metabolomics will be highlighted, as well as the recent trends in mass spectrometry-based single cell platforms. Additionally, some of the limitations of single-cell metabolomics and its recent applications will be briefly discussed.
\end{abstract}

(C) 2019 Elsevier B.V. All rights reserved.

\section{Introduction}

Cellular heterogeneity is ubiquitous in biology but poorly understood due to technical challenges. Various genetic, epigenetic and environmental factors contribute to cellular heterogeneity [1-3]. Cells can show heterogeneity in morphology, physiology and pathology, thus highlighting the necessity to study the biochemical and physiological characteristics of individual cells and their

Abbreviations: Da, Dalton; FACS, fluorescence assisted cell sorting; CTC, circulating tumor cell; PDMS, polydimethylsiloxane; MS, mass spectrometry; MALDI, matrix assisted laser desorption/ionization; TOF, time-of-flight; MAMS, microarrays for mass spectrometry; LDI, laser desorption ionization; SIMS, secondary ion mass spectrometry; ESI, electrospray ionization; FT-ICR, Fourier transform ion cyclotron resonance; FWHM, full width at half maximum; CE, capillary electrophoresis; D1L left dorsal-animal; V1L, left ventral animal; SPE, solid phase extraction; MS/MS, tandem mass spectrometry.

* Corresponding author.

** Corresponding author.

E-mail addresses: a.mashaghi.tabari@lacdr.leidenuniv.nl (A. Mashaghi), hankemeier@lacdr.leidenuniv.nl (T. Hankemeier).

1 Contributed equally.

2 Contributed equally. environment. However, most of the current technologies focus on obtaining information about the cellular processes and functions from average cell populations, ignoring the unique behavior resulting from cell-to-cell variations [1]. Recent advances have enabled studying single-cell genome [4], transcriptome [5], morphology and mechanics [6]. The link between the genotype and phenotype of a single cell can be understood by complete molecular profiling of the cell, especially its metabolome since it offers the most accurate depiction of the cellular reaction network.

Metabolomics is the study of small molecular weight compounds, typically less than 1500 Da [7]. It offers a comprehensive profiling of the full complement of small molecules. In comparison to other omics studies, characterization of the metabolome is difficult to achieve mainly due to complex diversity of the metabolites. Contrary to genomics, the inability to amplify metabolites, coupled with their high degree of dynamical changes, present a unique challenge in metabolomic studies. Notwithstanding, the large diversity of metabolic classes which makes developing a universal platform for metabolomic analysis a challenging task $[2,8]$. In addition, single-cell metabolomics exhibit its unique set of challenges. First, depending on the cell size, sample volume can go 
as low as few femtoliters or less which complicates cell sampling, preparation, and analysis. Furthermore, the wide dynamic range of metabolite amounts per cell stands in the way of any given analytical technique to cover the whole metabolome of the cell. Overall, the small sample volume combined with the inability of amplification makes it exceedingly difficult to analyze metabolites on the single cell level in an accurate, reliable, and reproducible manner.

However, significant progress has been made in the development of sample preparation and bioanalytical tools for single-cell metabolomics, revealing the unexploited potential of single cell metabolomics in several fields of applications. This review focuses on the recent developments in single-cell isolation and analytical techniques that are especially suited for single-cell metabolomics, with special focus on mass spectrometry-based analytical platforms. Additionally, some of the recent applications and current challenges are briefly highlighted.

\section{Discussion}

\subsection{Sample preparation}

As in any analysis, unravelling the metabolome on a single cell level usually starts with sample preparation. The main goal of sample preparation in single cell metabolomics is not only to isolate and prepare single cells for further downstream analysis, but to do so in a minimally disruptive manner to the cell and its microenvironment. This is due to the rapid changes of metabolite concentrations depending on the cell condition and its surrounding environment. It is also worth mentioning that conventional cell pretreatment approaches such as trypsinization and cell scraping are wholly unsuitable for metabolome analysis, doubly so on the single cell level due to metabolite leakage [9]. Thus, it is recommended to halt the enzymatic and metabolic activity of the cell directly after sampling, while preserving the integrity of the cell membrane to reduce metabolite leakage. To this end, in adherent mammalian cells, a washing step with PBS, followed by quenching with cold $\left(-50^{\circ} \mathrm{C}\right)$ mixture of $60 \%$ methanol and $70 \mathrm{mM}$ HEPES buffer resulted in minimum intracellular metabolites leakage [10].

Several cell isolation and manipulation approaches have been used to prepare single cells for analysis while causing minimal disruption to their microenvironment. Some of these methods are: fluorescence activated cell sorting (FACS), microfluidic arrays and pipette-based micromanipulation [11-13]. FACS excels at sorting fluorescently labeled cell populations into two or more subpopulations which can be analyzed by other methods. However, FACS measurements are largely unrelated to the metabolome of cells, therefore, it is mostly used, in conjunction with other sampling techniques, in isolating rare cell populations such as circulating tumor cells (CTCs) followed by their subsequent mass spectrometry analysis [14]. On the other hand, pipette-based micromanipulation, and microfluidic arrays are more readily integrated into single-cell metabolomics' analysis platforms, however, each comes with its own set of advantages, limitations and possible applications which will be briefly mentioned in this section.

\subsubsection{Pipette-based micromanipulation}

Microscale pipettes have been increasingly used to isolate and sample live single cells in their native environment [11]. Traditionally, single-cell sampling using pipette-based micromanipulation starts by observing and choosing target cells suspended in a normal culture dish or 96-well plate by the aid of microscopy. Then, a motorized stage or micromanipulator is used to move a tapered glass capillary to the proximity of the cell in question. Finally, aspiration is done by applying negative pressure to the micropipette where the whole cell, or its cytoplasm can be sampled, the aspirated sample can then be dispensed into a collection vessel by applying positive pressure on the capillary as shown in Fig. 1(A) [15-18]. Typically, this process is done manually at the expense of throughput, which is a critical limitation in largescale single-cell studies.

Despite its utility in visualizing and sampling live single cells, single-cell micromanipulation is often a laborious affair involving skilled personnel and prolonged periods of time. Thus, to adapt this method to wide scale use, several improvements must be made in terms of throughput, high skill requirements and overall convenience. To this end, several automated methods have been developed that are capable of single-cell manipulation [19-21]. One recent system that is suitable for suspended and adherent cells works by automatic selection of cells of interest depending on their visual characteristics by image analysis [22]. Then, a robot aspirates the desired cell by using a vacuum system attached to a tapered glass capillary. Finally, the cell is dispensed in a 3D printed microwells on a petri dish for subsequent analysis by the analytical method of choice. By automating target selection and sampling, this system was able to improve upon the throughput of manual micromanipulation by several orders of magnitude (from dozens of cells per day to over a thousand cells per day), while maintaining the inherent advantages of single cell micromanipulation, e.g. minimal disruption the cells' microenvironment, label-free selection, and simultaneous visual observation of cells.

While automated systems improve upon throughput and ease of use, they do so by increasing instrumental complexity and cost. On the other hand, manual systems are relatively simple and costeffective, but their throughput is largely limited by human factors, not to mention the high skill requirements for efficient sampling. As always, it is best to select a platform depending on the research goal. For large-scale systems biology and cell heterogeneity studies, automated micromanipulation systems would be a good choice. But, in the case of small-scale experiments, where a few dozen cells are needed, a simple setup involving a microscope with a manual micromanipulator might be sufficient.

\subsubsection{Microfluidics and lab-on-a-chip systems}

Contrary to the serial method of isolation in the previous methods, microfluidics or lab-on-a-chip systems aim to isolate cells in parallel by passing cells through microfluidic channels, which results in their separation into individual cells that can subsequently be collected in wells or storage vessels as shown in Fig. 1(B) [23]. Due to their miniaturized and parallel architecture, they have several inherent advantages over traditional cell separation methods. Among these advantages are their scalability, high automation potential, reduced reagent costs, and the possibility of performing multiple analytical assays simultaneously [24].

Recently, there were many innovations that incorporated microfluidics in single cell isolation and subsequent analysis. One example is a droplet-based microfluidics platform that divides blood samples into small nanoliter aqueous droplets that are embedded in oil, each droplet contains a single cell and its secretions [25]. This platform was subsequently used to detect rare circulating tumor cells in blood, based on their altered metabolic profile, due to their excessive lactic acid secretion in comparison to normal blood cells. Another technique incorporates a hydrodynamic trap in a pipette tip that allows for single-cell isolation from low cell-population suspensions (5-10 cells/ $\mu \mathrm{L}$ ) [26]. Additionally, an array of nano wells that are capable of trapping single cells by utilizing passive hydrodynamic flow and the least flow resistance path principles. This system has the advantage of having greater capture rates of single cells in comparison to others (almost $100 \%$ capture rates of single cells) [27]. 


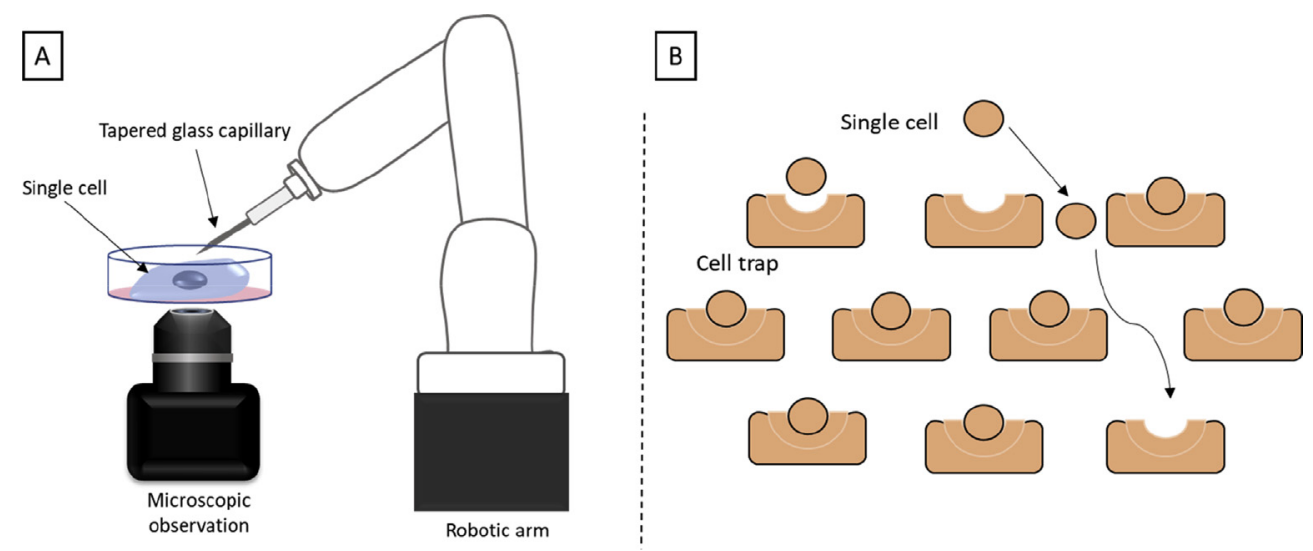

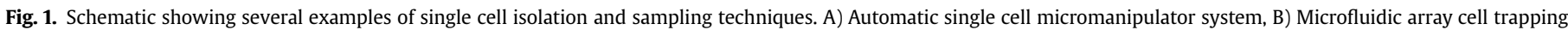
system.

Microfluidic-based systems have been used extensively in systems biology $[28,29]$, however, they are known to be difficult to couple with techniques used in metabolomics studies such as mass spectrometry. This is largely due to the inherent difficulty of sampling picolitre volumes from the microfluidic device with minimal sample loss, as well as using of polydimethylsiloxane (PDMS) as a construction material which has a significant background signal [30]. The latter issue could be resolved by using glass as a construction material, but this often increases manufacturing complexity and cost [31]. Despite these pitfalls, several techniques succeeded in coupling microfluidic systems with MS systems, highlighting their potential as a comprehensive single cell isolation and analysis platforms. Another issue that arises from using microfluidic platforms in single cell metabolomics studies is their sensitivity to variations in cell size, thus limiting their use in heterogenous cell cultures. Finally, the isolation process could cause perturbations in the metabolome, due to the interruption in cell-cell communication [32], possible reduction in cell growth, and restriction on cell shape imposed by the dimensions of the traps [33,34].

\subsection{Analytical techniques}

Despite the presence of multiple analytical techniques suited for analyzing organic molecules, there are several issues to keep in mind when choosing the optimal method for single cell metabolomic analysis. First, unlike nucleic acids, metabolites' signal cannot be amplified, which presents a significant challenge, especially when dealing with the small volumes associated with single cells (usually in the picolitre scale). Thus, the sensitivity of the analytical technique is of utmost importance in single cell metabolome studies. Moreover, to gain a complete picture of the metabolome, the analytical technique of choice must possess sufficient selectivity for molecular characterization of individual unlabeled metabolites, as well as being exhaustive enough to cover a wide range of metabolites. Keeping these considerations in mind, mass spectrometry has gained prominence as the method of choice in single cell metabolomic studies since it possesses the necessary sensitivity to reliably detect molecules in the single cell scale, as well as its molecular profiling capability which is perfectly suited for detection of unlabeled metabolites.

Accordingly, there are multiple techniques which utilize MS that possess the necessary sensitivity, accuracy and resolution for single cell metabolomics. Some of these methods, along with their uses, limitations and possible improvements are highlighted in this section.

\subsubsection{Matrix-assisted laser desorption/ionization}

Matrix-assisted laser desorption/ionization mass spectrometry (MALDI-MS) is one of the main techniques used for studying large molecules while causing minimal fragmentation. Typically, MALDIMS measurements start with mixing the desired sample with a matrix, followed by irradiation with a UV laser beam under vacuum condition. Subsequently, analytes are ionized and accelerated to a mass spectrometer analyzer (traditionally, a time-of flight (TOFMS)) [35]. Owing to the recent developments in optics and the incorporation of nano-particle matrices, MADLI-MS has been reliably used for traditional single-cell analyses as well as 2D and 3D imaging of metabolites in cellular and sub-cellular space [36-39]. However, as with most single cell analysis techniques, achieving high throughput is always a challenge. An interesting platform that attempts to alleviate this issue was proposed by Ong et al., in which, the process of optical imaging of single cells followed by MALDITOF analysis, was automated [40]. Accordingly, this platform was successfully used in phenotypic classification of rat cells according to their metabolome. Another promising high-throughput platform utilized microarrays for mass spectrometry (MAMS) to automatically isolate single cells by using hydrophilic reservoirs [41]. Then, cells were co-crystallized within the confines of the reservoirs with 9-aminoacridine, which led to increased sensitivity in comparison to traditional MALDI-MS methods. Finally, the metabolomic differences between environmentally and genetically perturbed Saccharomyces cerevisiae cells on the single cell scale were observed utilizing the same platform [42].

There are some limitations when MALDI-MS is employed in single cell metabolomics. First, traditional MALDI-MS methods usually sample the cell in vacuum after extensive sample preparation, which goes against the ethos of metabolomic studies, i.e., sampling the cell in its native environment to minimize metabolic changes. Consequently, several techniques tried to utilize ambient conditions for ionization followed by traditional MS measurements (albeit at the possible expense of sensitivity) [43]. Moreover, due to its use of low molecular weight organic compounds in the matrix preparation, reliably measuring most of low molecular weight metabolites (less than $800 \mathrm{Da}$ ) is often a difficult task, due to interference from the matrix signals [44]. In addition, the usage of UV laser might be detrimental to the cell condition, especially in the case of fragile cells that might disintegrate easily upon mixing with the matrix and its subsequent laser bombardment [45]. However, multiple techniques are proposed to address these limitations, among these techniques is an approach that utilizes visible-wave MALDI coupled with a low background signal matrix that can protect, to some extent, cells from absorbing excessive laser energy. 
This method was used to successfully analyze single cells from several cell lines, highlighting the specific phenotype variations among them [46].

An interesting approach that also attempts to circumvent the limitations of traditional MALDI-based methods is matrix-free laser desorption/ionization (matrix-free LDI). Among the many strategies of achieving matrix-free LDI is replacing the matrix with nanostructures [47]. The nanostructures replace the function of matrices by acting as nanoantennae that harvest light from the laser followed by subsequent ionization of the sample, a process termed nanophotonic ionization-LDI [48,49]. An enhanced nanophotonic-ionization LDI technique was proposed by Walker et al. [50]. They utilized silicon nano post arrays in a matrix-free LDI-MS system in which, $S$. cerevisiae single cells were analyzed. Changes in the metabolome, owing to oxidative stress, as well as intra and inter-population differences were discerned. Due to its superior performance in analyzing small molecular weight compounds, matrix-free LDI was also utilized in several imaging mass spectrometry platforms [51,52]. However, the relatively large spot size (few micrometers) makes MALDI and LDI single cell imaging techniques suitable for relatively large cells only. Wang et al. attempted to circumvent this limitation by utilizing vacuum ultraviolet laser coupled to a TOF mass analyzer that could achieve sub-micron resolution with the added benefit of acquiring fluorescent signals during the mass spectrometry imaging process [53], in which, they succeeded in imaging several metabolites in singleHeLa cells, with minimal fragmentation and higher sensitivity than traditional imaging mass spectrometry approaches. However, if a higher resolution is needed, secondary ion mass spectrometrybased methods are traditionally used instead.

\subsubsection{Secondary ion mass spectrometry imaging techniques}

Secondary ion mass spectrometry (SIMS) recently emerged as a promising MS imaging technique that is capable of single cell and sub-cellular resolutions [8]. Fundamentally, SIMS works by directing a primary pulsed ion beam on the sample surface and measuring the secondary ions ejected using a mass spectrometer as shown in Fig. 2 [54]. Typically, time-of-flight MS (TOF-MS) is used

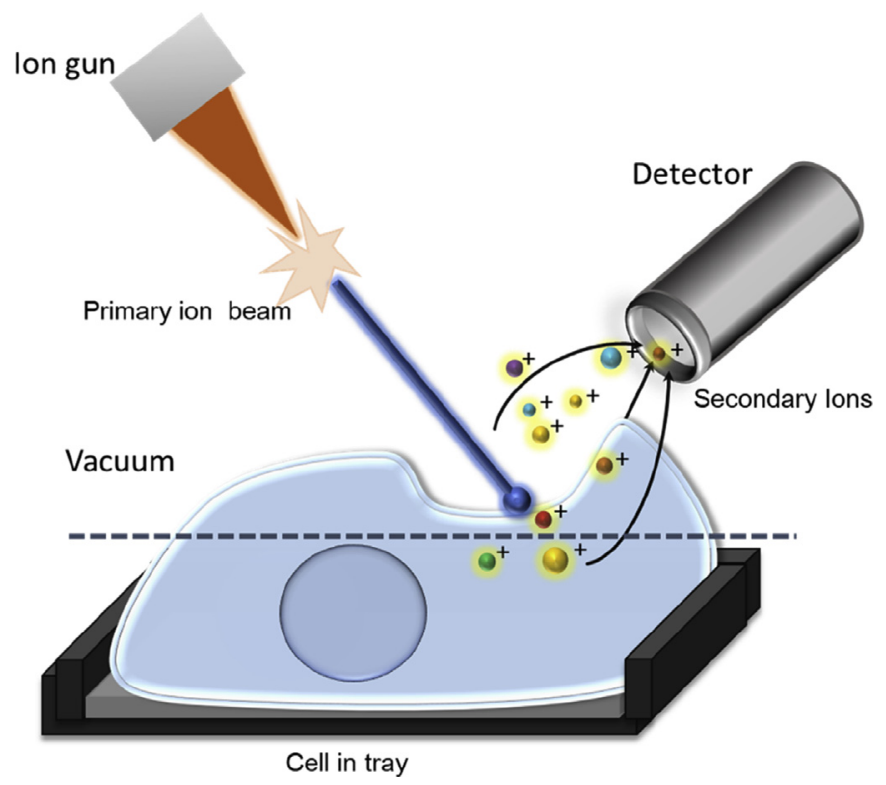

Fig. 2. Schematic showing the mechanism of secondary ion mass spectrometry (SIMS), in which, a primary ion beam is directed at the sample surface resulting in secondary ions which are subsequently measured by mass spectrometry. due to its exceptional acquisition rates and dynamic range. By contrast to MALDI-MS and matrix-free LDI imaging, SIMS imaging methods can achieve submicron lateral resolutions, combined with its nanometer depth resolution. Therefore, SIMS-based techniques are uniquely suited for studying the distribution of endogenous and exogenous species in the sub-cellular space. This was demonstrated by visualizing the sub-cellular, 3D distribution of the drug amiodarone and cellular metabolites in single macrophage cells by using TOF-SIMS, showing the high affinity of the drug to the surface and subsurface regions of microphages [55]. Another study succeeded in measuring the drug induced changes in metabolites in single HeLa cells, the analysis was done in a high throughput manner by integrating single cell microarrays with automated TOF-SIMS acquisition [56]. Furthermore, the 3D depth profiling accuracy of TOF-SIMS was validated by comparing the spatial distribution of polymeric nanoparticles measured by SIMS within HeLa cells with 3D optical data obtained by fluorescence labeling of polymeric nanoparticles [57].

Despite SIMS utility at 3D label-free imaging of biological samples [58], there are several limitations that should be kept in mind. First, typical SIM-based techniques are incapable of carrying out simultaneous full scan and MS/MS analyses, an issue that is exacerbated by the possible isobaric interferences caused by the primary beam. A possible solution to this issue was presented by Fisher et al., in which a modified SIM-TOF design allowed for parallel full scan measurements of a desired mass range and MS/MS target identification that improves upon the identification power of traditional SIM methods significantly [59]. Moreover, since most of SIM-based techniques utilize TOF-MS as the MS analyzer, they share some of its limitations, such as the lower mass resolution relative to other MS analyzers. Finally, despite SIMS methods' high performance in 3D imaging, it comes at the price of throughput since the methods can either be optimized for high throughput with less lateral and depth resolution, or high resolution with low throughput. An interesting approach that intends to address some of the previously mentioned limitations involves coupling a TOFMS with an orbitrap, which allowed for fast 3D acquisition of single cells by using the TOF analyzer, followed by high mass accuracy and resolution measurement of an area of interest using the orbitrap analyzer, with an optional MS/MS fragmentation [60].

\subsubsection{Electrospray ionization mass spectrometry}

Electrospray ionization mass spectrometry (ESI-MS) is considered as a "soft" ionization technique like MALDI. However, in contrast to most MALDI and SIMS-based methods, ESI-MS methods ionize the sample in ambient conditions with minimal pretreatment, thus minimizing the disruption of the cell and its metabolome. The utility of ESI-MS techniques in metabolomics has increased by the incorporation of high resolution, accurate mass instruments such as Fourier transform ion cyclotron resonance-MS (FT-ICR-MS) and orbitrap-based instruments [61]. FT-ICR-MS and orbitrap MS are powerful tools in metabolomic studies that can achieve ultrahigh resolution $(>1,000,000$ FWHM and 240,000 FWHM, respectively) and accurate mass ( $<1 \mathrm{ppm})$ at the possible expense of acquisition time.

One of the prevalent techniques that employs ESI-MS is known as "live single cell mass spectrometry" (LSC-MS), in which a metal coated capillary is used to sample live single cells or single organelles, followed by nano-ESI-MS measurements of the capillary contents after the addition of a suitable organic solvent as shown in Fig. 3 [62]. This method has been successful in discerning the metabolic differences and identifying specific metabolites of single mammalian [63] and plant cells [17]. Recently, this method was also used to distinguish the localization of terpenoid indole alkaloids in specific cell types from Catharanthus roseus stem tissues [64]. While it is 


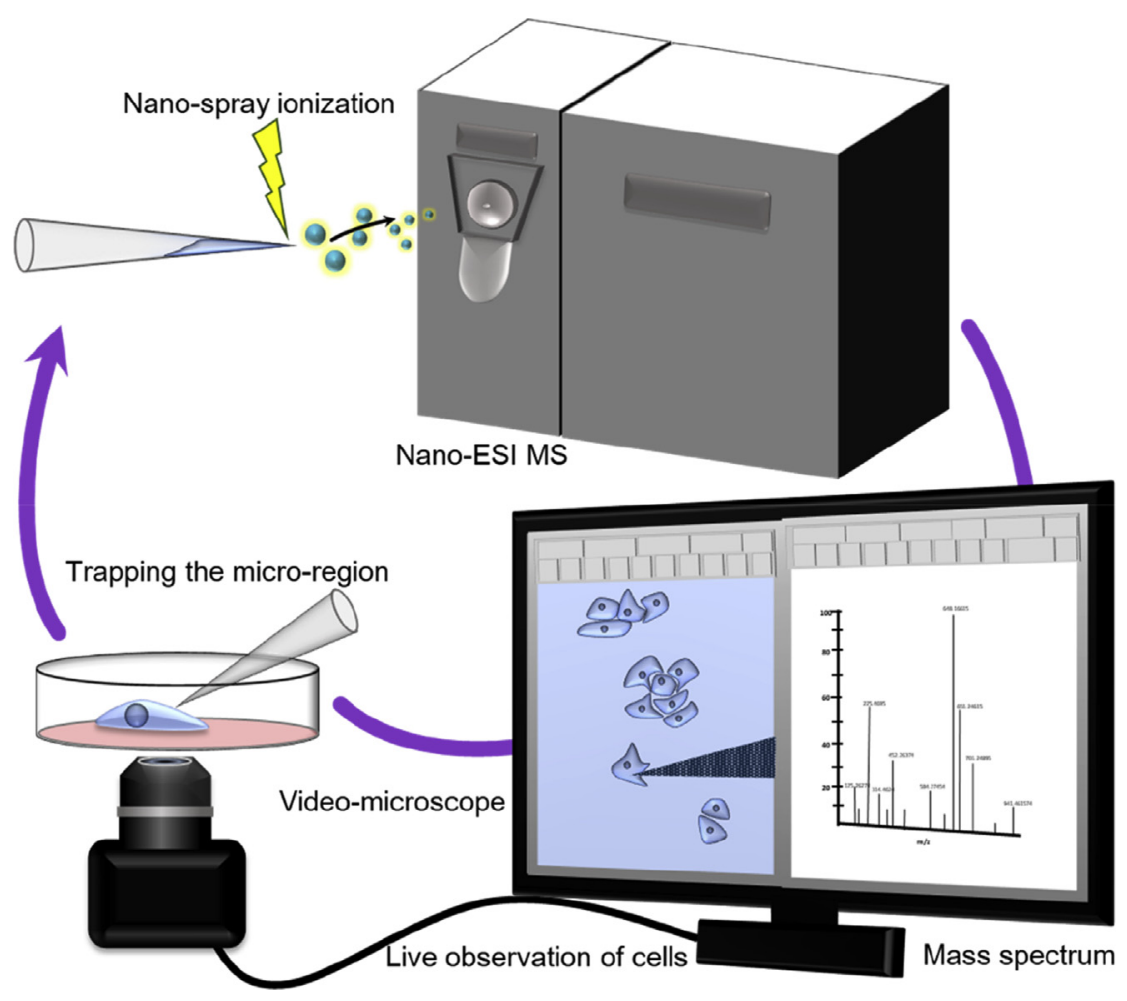

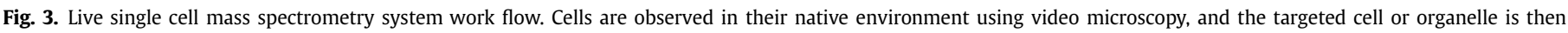
sampled using a tapered glass capillary. The capillary's content is directly introduced to a nano-ESI mass spectrometer after the addition of an ionization solvent.

arguably the best in direct sampling of single cells in their native environment, this comes at the expense of throughput due to the multistep process that also limits the real-time detection. Pan et al. achieved a higher throughput as well as real-time analysis by employing a probe-based approach termed "Single-probe MS", which is capable of sampling and ionizing the intracellular components of live single cells in one step [65]. This miniaturized, multifunctional system incorporates a "Single-probe" which consists of a laser-pulled dual-bore quartz needle, a solvent-providing capillary and a nano-ESI emitter. The dual-bore needle portion is inserted into single cells to sample intracellular components, in which, the solvent flows in the first channel (the solvent-providing capillary) to the second channel (nano-ESI emitter) through a liquid junction located at the sampling site inside the cell. An ionization voltage of $(\sim 3 \mathrm{kV})$ is transmitted through the solution to allow the extraction and ionization of the intracellular components and subsequent measurement by nano-ESI-MS. This approach was used to analyze drug treated and untreated individual HeLa cells in which, several cellular metabolites and lipids were detected in both positive and negative ion mode. In drug treated cells, the anticancer compounds doxorubicin, paclitaxel and OSW-1 were successfully detected in single HeLa cells. Additionally, negatively charged cellular metabolites from single HeLa cells analysis in positive ion mode could be achieved through the addition of dicationic ion-pairing compounds [66] as well as monitoring the metabolic changes of single phytoplankton cells under different environmental conditions [67]. The same group improved upon their previous design with a simpler "T-probe" system that incorporated the junction orthogonally between the sampling channel and the nano-ESI channel (Fig. 4), this system was then used to analyze the metabolic changes of single HeLa cells upon treatment with anticancer drugs [68].

A different approach with an improved resolution combines capillary micro sampling with ESI-MS and ion mobility separation (ESI-IMS-MS) [69]. This improved platform was then used to assess the metabolic and the lipidomic profile changes of single human hepatocytes upon treating cells with rotenone drug, the changes in the distribution of the adenylate energy charge was accurately measured. Moreover, the incorporation of ion mobility separation process reduced the chemical background, which resulted in doubling the number of the detected metabolites and the tentative annotation of $\sim 23$ metabolites per single cell [70]. Another recent platform involves the integration of patch clamp sampling technique with nano-ESI-MS for the analysis of single neurons from mouse brain [71]. This unique integration allowed rapid and sensitive profiling of the metabolic and the physiological state of a single neuron, as well as the identification of more than 50 metabolites from the cytoplasm of a living neuron, highlighting its potential as a useful tool in neuroscience research.

One limitation that the previous studies shared is their inadequate quantitation performance. Admittedly, several challenges stand in the way of metabolites' quantitation on the single-cell level [72]. Controlling the exact volume sampled, precise extraction of cellular contents, and accurate and sensitive analysis of the extracted analytes followed by their subsequent quantitation are examples of the aforementioned challenges. However, a recent study succeeded in addressing some of these challenges by quantifying glucose extracted from single Allium cepa epidermal cells using electroosmotic extraction and nano-ESI MS [73]. Electroosmotic extraction from live cells was achieved using two electrodes and a finely pulled nanopipette containing a hydrophobic electrolyte (Fig. 5). Extracted analytes were electro-osmotically dragged from the cell into the pipette for subsequent nano-ESI MS analysis. The extracted volume can be precisely controlled by controlling the applied voltage between the two electrodes and the extraction time. Extracted glucose was successfully quantitated using an internal standard (glucose- $d_{2}$ ) of known concentration.

Most of the previously mentioned ESI-MS-based techniques provide direct, rapid and real-time analysis of metabolites and 


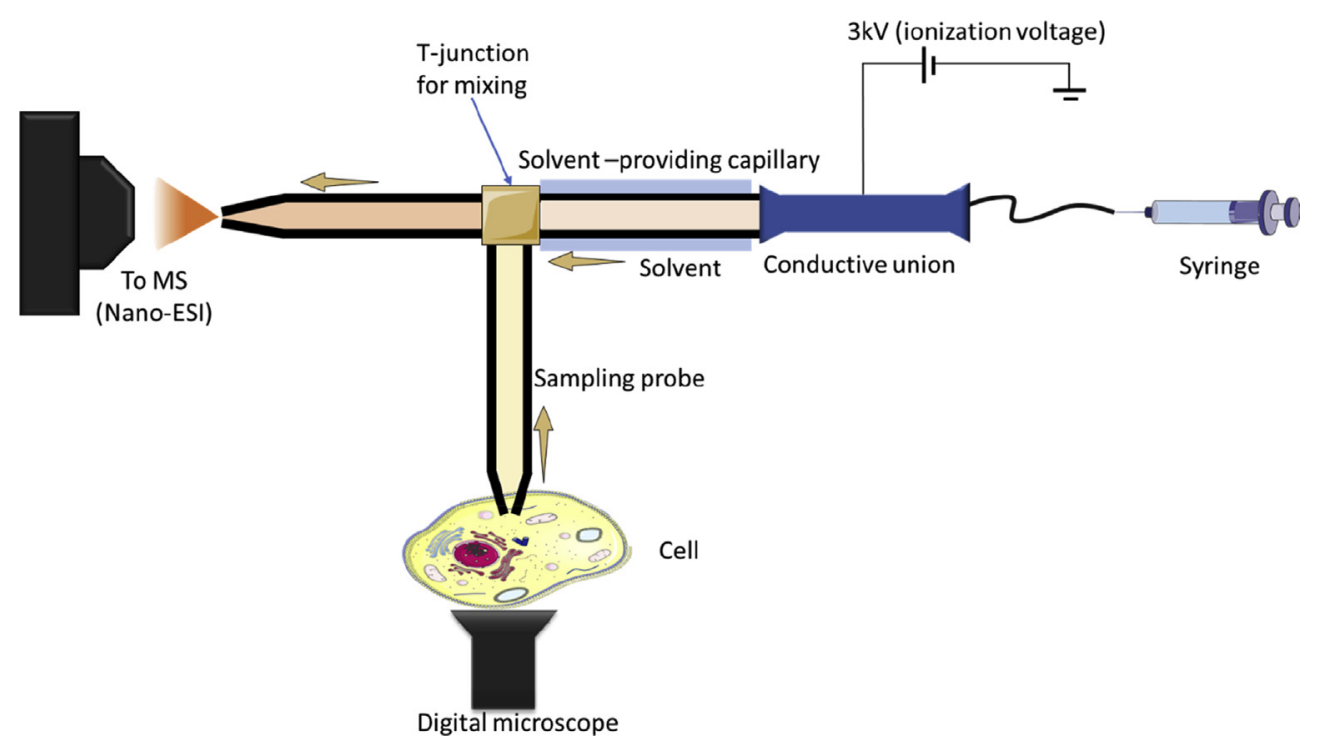

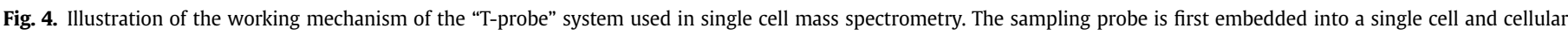

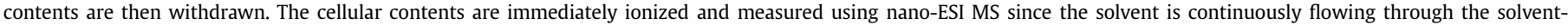
providing capillary into the nano-ESI emitter.

lipids at the single cell scale. From a metabolomic point of view, ESIMS-based methods are arguably best suited for analyzing cells at their native environment with minimal disruption. However, they are inherently more susceptible to matrix effects due to the absence of a separation step before MS analysis, which also results in low metabolite coverage.

Separation-based methods coupled to ESI-MS techniques such as capillary electrophoresis MS (CE-MS) attempt to address some of the limitations of ESI-MS. Over the past few years, the use of electrophoretic separation (CE) coupled with ESI-MS in metabolomic studies has increased significantly. In capillary electrophoresis, ions are typically separated based on their electrophoretic mobility, mainly dependent on the charge and the size of the molecule, which makes CE-based techniques the favored method for the analysis of highly polar and charged metabolites. The recent technological developments in CE-MS approaches resulted in achieving higher separation efficiency, and improved concentration sensitivity, allowing the identification and/or quantification of metabolites on the single cell scale [74]. CE-MS coupling benefits from the advantages of both CE and MS, providing sensitive, swift and wide range analysis of metabolites [75]. In addition, CE inherently requires small loading volumes, which is advantageous in single cell studies. Recent studies demonstrated the potential of applying single cell CE-MS in the fields of biomedical, clinical, and plant metabolomics. An interesting platform combined patch clamp electrophysiology with CE-MS to interrogate the metabolic profile of GABAergic and glutamatergic neuron cells on the subcellular scale [76]. The study revealed metabolic differences between the two cell types and succeeded in detecting both common and cell-type specific metabolites (i.e., GABA in GABAergic cells), highlighting the chemical heterogeneity between GABAergic and other neuron cells. Furthermore, a more recent study demonstrated metabolic heterogeneity between the 8- and 16-cell embryo of South African clawed frog (Xenopus laevis) by utilizing microprobe single-cell CE-ESI-MS [77]. The study illustrated different metabolic activity across the dorsal-ventral axis and successfully detected specific molecules (i.e. asparagine and glycine betaine) in the left dorsal-animal (D1L cell) which were not found in the left-ventral animal (V1L cell), showing the differences in the metabolic activity between cells derived from the same hemisphere.

Although, CE-MS-based techniques showed great potential and, to date, a promising performance, they still face several pitfalls and challenges hindering their widespread use in the field of single cell metabolomics. Among these challenges are: method robustness,

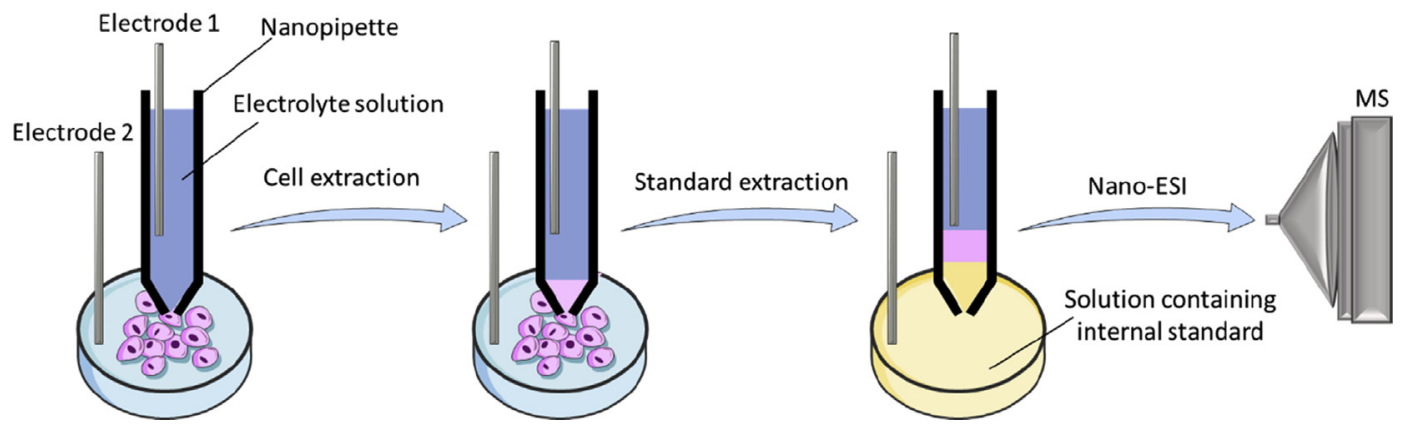

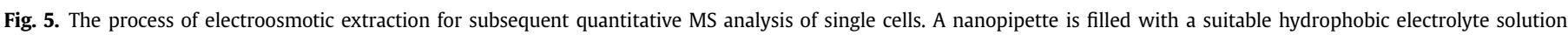

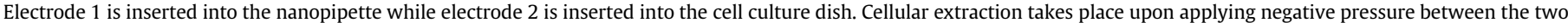

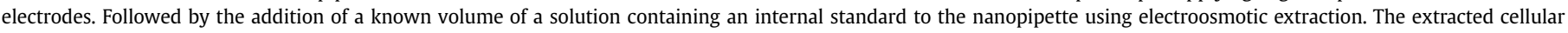
contents are subsequently analyzed using nano-ESI MS. 
migration time variability, poor concentration sensitivity (due to small sample volume injections) and postcapillary dilution upon the use of a coaxial sheath liquid interface [78]. However, this could possibly be mitigated with the incorporation of patch clamp or any similar sampling approach to improve specific cells' selection. Nevertheless, significant progress has been made in the development of novel interfaces for coupling CE to MS which offers new perspectives for highly sensitive and robust metabolic profiling of various samples as shown in Fig. 6 [79]. An interesting solution that combines the advantages of MALDI and CE-MS has been used lately to improve method throughput and metabolite coverage on a single cell level, in which, MALDI was used for metabolite guidance to the CE-ESI-MS instrument [80]. In addition, improvements in CE-MS detection sensitivity for metabolic profiling can also be achieved by using sample pre-concentration techniques such as solid phase extraction (SPE) systems [74]. Overall, CE-MS systems excel at analyzing highly polar metabolites which constitute a major fraction of known metabolites involved in primary metabolism [81].

\subsection{Recent applications}

Single cell metabolomics exhibit a great potential in the advancement of several fields, on two fronts. First, it provides a comprehensive picture about the cellular dynamic and its phenotypic fingerprint, through adding an extra dimension to the flow of information from DNA to RNA to proteins to finally metabolites. In addition, single cell resolution studies reveal crucial information about individual cells that were often unattainable by traditional population-based studies $[82,83]$. Hereby, we summarize some of the recent applications of single cell metabolomics in biological, pharmaceutical, and medical sciences.

\subsubsection{Biological}

Studies of the plant metabolome offers an insight on the complex cellular dynamic diversity and processes responsible for plant response to abiotic stress [84]. Thus, understanding cellular mechanisms and identifying stress-responsive metabolic pathways will aid significantly in developing adaptive strategies for plants' survival and growth. Single cell metabolomics demonstrated the dynamic cellular processes of the encystment of fresh water algae (Haematococcus pluvialis) through monitoring ATP, ADP, astaxanthin and $\beta$ carotene in single cells [85]. The study succeeded in detecting 13 metabolites on a single cell level as well as highlighting the correlation between the reduction of ATP/ADP ratio and the accumulation of astaxanthin. Another group succeeded in analyzing single cells obtained from petal, leaf and stem of wild malva (Pelargonium zonale) [86]. Several compounds (i.e., geraniol, terpenoid and methyl citronellate) were successfully identified together with specific metabolites to each cell type (petal, leaf and stem).

Moreover, due to the inherent chemical complexity of neurotransmitters and neuropeptides, metabolic characterization of neurons on the single cell level can help in understanding complex neural communications. Potentially aiding in the development of new approaches for understanding and treating persistent neurological disorders [87]. Single cell metabolomics revealed the metabolic differences not only between different neuron types, but also neuron cells originating from the same genotype or even having similar phenotype. This was achieved by studying the isolated neurons of Aplysia californica, where over 300 metabolites were successfully detected in neurons obtained from different neuronal cell types [88]. Another study incorporated single-cell mass spectrometry with isotopic labeling to detect molecular and cellular changes in single neurons upon moderate UV exposure. In the study, single-cell measurements of hippocampal (HPC) neurons in mice revealed elevated urocanic acid (UCA) levels upon moderate UV exposure [89]. Furthermore, a novel glutamate biosynthetic pathway in the brain was discovered in which, UCA was converted to glutamate that lead to neurobehavioral changes, mainly, improvements in learning and recognition memory.

\subsubsection{Pharmaceutical}

Metabolomics is not only limited to the study of endogenous molecules, but it also includes the study of exogenous molecules such as detecting and quantifying drugs and their metabolites for drug discovery and development purposes. In pharmaceutical industry, there is an increased interest in analyzing and quantitating the spatial distribution of drugs and their metabolites on a single cell level, which will provide a better understanding about the pharmacokinetic and dynamic characteristics of drugs that is essential for: target validation studies, improving drug efficacy and reducing failure rates, especially at the late stage of drug development $[90,91]$. Recently, a study was done on single yeast cells ( $S$. cerevisiae) [42], where the cells were chemically perturbed with 2deoxy-D-glucose to monitor its effect on the single cells. The study reported quantitative variations in glycolytic metabolites and ATP/ ADP ratio and showed that detection of a specific drug metabolite (2-deoxy-d-glucose-6-phosphate) could be achieved. A more recent study [60] included the incubation of rat alveolar macrophage cells with different concentrations of amiodarone drug followed by the evaluation of the metabolic profile of individual cells. The study showed the correlation between the upregulation of phospholipids and cholesterol with the accumulation of amiodarone. It also showed high degree of variability in drug uptake and the phospholipids concentrations between single cells. Accordingly, accounting for cellular heterogeneity is crucial for gaining a comprehensive picture about drug's pharmacokinetic and pharmacodynamic properties on the single cell level.

\subsubsection{Clinical}

Metabolomics has a largely untapped potential in improving cancer diagnostics and prognostics through the characterization of the unique cancer metabolome as well as monitoring any

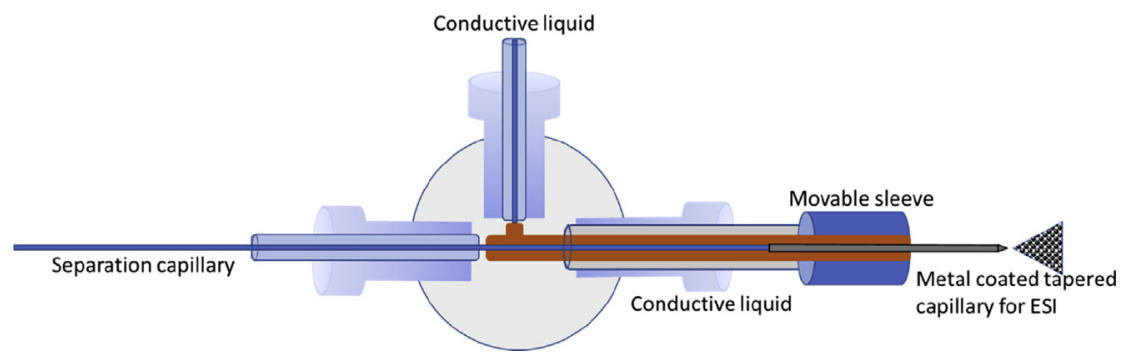

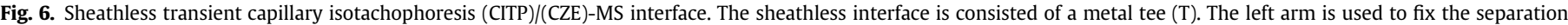

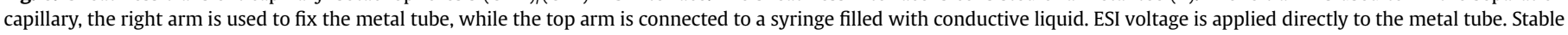
nano-ESI spray is achieved through the electric contact between the ESI voltage power supply and the CE separation liquid done through the conductive liquid. 
Table 1

Open-access software tools that offer end-to-end data processing, analysis, annotation and interpretation of MS-based metabolomic studies.

\begin{tabular}{|c|c|c|c|c|}
\hline Tool & Analytical technique & Compatible file formats & Software type & References \\
\hline XCMS online & Chromatography-based MS & AIA/ANDI NetCDF, mzXML, mzData and mzML & Web App & [103] \\
\hline MALDIquant & Direct-MS (MALDI and Infusion-based methods) & $\begin{array}{l}\text { txt, csv, Bruker fid, Ciphergen XML, mzXML, } \\
\text { mzML, imzML, Analyze 7.5, CDF, mMass MSD }\end{array}$ & R Package & [104] \\
\hline Galaxy-M & $\begin{array}{l}\text { Chromatography-based MS and direct infusion } \\
\text { MS methods }\end{array}$ & DI-MS: Thermo Raw files, datLC-MS: mzML & Galaxy & [102] \\
\hline Workflow4metabolomics & Chromatography-based MS methods & mzML, mzXML, Thermo Raw files & Galaxy & {$[105]$} \\
\hline MetaboAnalyst 3.0 & Chromatography-based MS methods & mzXML, NetCDF, mzDATA, csv, txt & Web App & {$[106]$} \\
\hline MAIT & LC-MS & mzData, NetCDF & R Package & [107] \\
\hline
\end{tabular}

alterations in it. Moreover, metabolites of small molecular weight can provide mechanistic insights into novel biomarkers for diseases. A prime target for single cell metabolomics in cancer studies are CTCs, due to their low concentrations in the peripheral blood (1-100 cells per $7.5 \mathrm{ml}$ ) [92]. CTCs are cells detached from the primary tumor circulating into the blood stream and they are believed to have a great role in cancer metastasis. Thus, CTC metabolomic profiling has a tremendous potential in providing information about the tumor composition and allowing for the study of tumor relapse and resistance. However, due to CTCs' scarcity and difficulty to be isolated, enriched and analyzed, very limited studies have succeeded to investigate their metabolic profile on a single cell scale. One of the studies that depicted potential results succeeded in acquiring the metabolic profile of a single CTC obtained from a neuroblastoma patient as well as detecting specific metabolites corresponding to the same cancer type [14]. Another study succeeded in identifying single circulating tumor cells, through measuring the elevated lactic acid concentration resulted from the Warburg effect specific only in cancer cells [25], demonstrating the utility of CTC metabolic profiling in future diagnostic applications. Recently, Zhang, et al. further highlighted the potential of MS-based single-cell metabolomics in differentiating between normal cells (astrocytes), and cancer cells (glioblastoma) [93]. This was achieved by integrating their previous droplet extraction [94] and pulsed direct current electrospray ionization MS [95] methods into one platform. This platform was then able to detect glioblastoma cells' unique features, such as the unique coexistence of $\mathrm{PC}(17: 1)$ and PE (20:1) which could only be discerned by using tandem mass spectrometry (MS/MS), a unique advantage offered by their integrated platform.

\section{Challenges and future prospects}

Despite the numerous techniques and applications in singlecell metabolomics, mass spectrometry-based single cell metabolomics still needs further development to become an established field. In addition to the considerations mentioned in Section 2.1 regarding sample preparation and isolation, other challenges must be addressed that make wide-scale use of single-cell metabolomics difficult. In particular, the difficulty to export single-cell metabolomic techniques to other laboratories/groups. This is largely due to low dissimilation of single-cell protocols, data, and metadata of metabolic studies by using public repositories such as MetaboLights [96], and metabolomics Workbench [97]. Sharing data improves reproducibility, confidence in the data itself, and allows for reuse and re-analysis in the future by other teams. The reporting of the aforementioned data should also be standardized. Goodacre et al. attempted to address this issue by proposing minimum reporting standards for data analysis in metabolomics [98], but compliance with said standards is not absolute yet [99].
Another issue that hinders wide-scale adoption of single-cell metabolomics is the relative lack of established end-to-end, open access data analysis platforms that are especially suited for metabolomics. This forces each laboratory to develop their own tools which hampers collaborative efforts as well as attempts to reproduce the results by other groups. This is complicated further by the diversity of the analytical techniques utilized in single cell metabolomics and, by extension, the file formats as well as the type of generated data. Hence, the development of a universal software tool that comprehensively process, analyze, and translate the data into biologically meaningful context is yet to be achieved in MSbased metabolomic studies [100,101]. This proposed tool should be platform independent, possess an open license, and must be capable of importing raw files, processing them, performing data analysis and producing an output. To this end, several software tools that attempt to perform that role have been proposed (Table 1), all of the included methods are freely available and can import open-source MS file formats such as mzXML, mzML, NetCDF, etc., while some of them are capable of importing commercial file formats as well [102].

\section{Conclusion}

In conclusion, despite the multitude of isolation, analysis, and data analysis techniques developed, no single-cell metabolomic method is flawless in all regards. Instead, the appropriate isolation and analytical technique should be selected based on the individual research goal in mind. Balancing the degree of invasiveness, throughput, and success rate of the isolation method while selecting the analytical technique with the desired sensitivity, exhaustiveness, and accuracy is not an easy task but it is essential for the success of single-cell metabolomic studies. Despite the pitfalls of single-cell metabolomics, the information gleaned from single cell studies cannot be produced in population-based assays. Therefore, in combination with other single cell omics approaches, new insights can be gained about the behavior of individual cells, and subsequently be applied in the fields of biology, medicine, and pharmaceutics.

\section{Acknowledgments}

The authors would like to thank Dr. Walaa Zarad, and Dr. Mohamed Ashraf for their invaluable assistance in carefully proof reading the manuscript and Dr. Tsutomu Masujima for his scientific guidance and support. This work was supported by The Ichiro Kanehara Foundation for the Promotion of Medical Sciences and Medical Care [grant number: 17RYU015]. AM and TH were funded by the research program IMMUNMET with project number 16249 , which is financed by the Netherlands Organisation for Scientific Research. 


\section{References}

[1] S.J. Altschuler, L.F. Wu, Cellular heterogeneity: when do differences make a difference? Cell 141 (2010) 559-563. https://doi.org/10.1016/j.cell.2010.04.033.

[2] R. Zenobi, Single-cell metabolomics: analytical and biological perspectives, Science 342 (2013) 1243259. https://doi.org/10.1126/science.1243259.

[3] A. Oikawa, K. Saito, Metabolite analyses of single cells, Plant J. 70 (2012) 30-38. https://doi.org/10.1111/j.1365-313X.2012.04967.x.

[4] I.C. Macaulay, T. Voet, Single cell genomics: advances and future perspectives, PLoS Genet. 10 (2014). https://doi.org/10.1371/journal.pgen.1004126. e1004126.

[5] A. Giustacchini, S. Thongjuea, N. Barkas, P.S. Woll, B.J. Povinelli, C.A.G. Booth, P. Sopp, R. Norfo, A. Rodriguez-Meira, N. Ashley, L. Jamieson, P. Vyas, K. Anderson, Å. Segerstolpe, H. Qian, U. Olsson-Strömberg, S. Mustjoki, R. Sandberg, S.E.W. Jacobsen, A.J. Mead, Single-cell transcriptomics uncovers distinct molecular signatures of stem cells in chronic myeloid leukemia, Nat. Med. 23 (2017) 692-702. https://doi.org/10.1038/nm.4336.

[6] V. Sheikh-Hasani, M. Babaei, A. Azadbakht, H. Pazoki-Toroudi, A. Mashaghi, A.A. Moosavi-Movahedi, S.N.S. Reihani, Atorvastatin treatment softens human red blood cells: an optical tweezers study, Biomed. Opt. Express 9 (2018) 1256-1261. https://doi.org/10.1364/BOE.9.001256.

[7] D.S. Wishart, D. Tzur, C. Knox, R. Eisner, A.C. Guo, N. Young, D. Cheng K. Jewell, D. Arndt, S. Sawhney, C. Fung, L. Nikolai, M. Lewis, M.-A. Coutouly, I. Forsythe, P. Tang, S. Shrivastava, K. Jeroncic, P. Stothard, G. Amegbey, D. Block, D.D. Hau, J. Wagner, J. Miniaci, M. Clements, M. Gebremedhin, N. Guo, Y. Zhang, G.E. Duggan, G.D. MacInnis, A.M. Weljie, R. Dowlatabadi, F. Bamforth, D. Clive, R. Greiner, L. Li, T. Marrie, B.D. Sykes, H.J. Vogel L. Querengesser, HMDB: the human metabolome database, Nucleic Acids Res. 35 (2007) D521-D526. https://doi.org/10.1093/nar/gk1923.

[8] S.S. Rubakhin, E.J. Lanni, J.V. Sweedler, Progress toward single cell metabolomics, Curr. Opin. Biotechnol. 24 (2013) 95-104. https://doi.org/10.1016/ j.copbio.2012.10.021.

[9] R.V. Kapoore, R. Coyle, C.A. Staton, N.J. Brown, S. Vaidyanathan, Cell line dependence of metabolite leakage in metabolome analyses of adherent normal and cancer cell lines, Metabolomics 11 (2015) 1743-1755. https:/| doi.org/10.1007/s11306-015-0833-4.

[10] R. Vijay Kapoore, R. Coyle, C.A. Staton, N.J. Brown, S. Vaidyanathan, Influence of washing and quenching in profiling the metabolome of adherent mammalian cells: a case study with the metastatic breast cancer cell line MDA-MB-231, Analyst 142 (2017) 2038-2049. https://doi.org/10.1039/ C7AN00207F.

[11] P. Hu, W. Zhang, H. Xin, G. Deng, Single cell isolation and analysis, Front. Cell Dev. Biol. 4 (2016). https://doi.org/10.3389/fcell.2016.00116.

[12] A. Gross, J. Schoendube, S. Zimmermann, M. Steeb, R. Zengerle, P. Koltay, Technologies for single-cell isolation, Int. J. Mol. Sci. 16 (2015) 16897-16919. https://doi.org/10.3390/ijms160816897.

[13] A.E. Vasdekis, G. Stephanopoulos, Review of methods to probe single cell metabolism and bioenergetics, Metab. Eng. 27 (2015) 115-135. https:// doi.org/10.1016/j.ymben.2014.09.007.

[14] E. Hiyama, A. Ali, S. Amer, T. Harada, K. Shimamoto, R. Furushima Y. Abouleila, S. Emara, T. Masujima, Direct lipido-metabolomics of single floating cells for analysis of circulating tumor cells by live single-cell mass spectrometry, Anal. Sci. 31 (2015) 1215-1217. https://doi.org/10.2116 analsci.31.1215.

[15] T. Ishøy, T. Kvist, P. Westermann, B.K. Ahring, An improved method for single cell isolation of prokaryotes from meso-, thermo- and hyperthermophilic environments using micromanipulation, Appl. Microbiol. Biotechnol. 69 (2006) 510-514. https://doi.org/10.1007/s00253-005-0014-x.

[16] J. Fröhlich, H. König, Rapid isolation of single microbial cells from mixed natural and laboratory populations with the aid of a micromanipulator, Syst. Appl. Microbiol. 22 (1999) 249-257. https://doi.org/10.1016/S0723-2020(99) 80072-1.

[17] T. Fujii, S. Matsuda, M.L. Tejedor, T. Esaki, I. Sakane, H. Mizuno, N. Tsuyama, T. Masujima, Direct metabolomics for plant cells by live single-cell mass spectrometry, Nat. Protoc. 10 (2015) 1445-1456. https://doi.org/10.1038/ nprot.2015.084.

[18] A. Ali, Y. Abouleila, S. Amer, R. Furushima, S. Emara, S. Equis, Y. Cotte, T. Masujima, Quantitative live single-cell mass spectrometry with spatial evaluation by three-dimensional holographic and tomographic laser microscopy, Anal. Sci. 32 (2016) 125-127. https://doi.org/10.2116/analsci.32.125.

[19] N. Yoshimoto, A. Kida, X. Jie, M. Kurokawa, M. Iijima, T. Niimi, A.D. Maturana, I. Nikaido, H.R. Ueda, K. Tatematsu, K. Tanizawa, A. Kondo, I. Fujii, S. Kuroda, An automated system for high-throughput single cell-based breeding, Sci. Rep. 3 (2013) 1191. https://doi.org/10.1038/srep01191.

[20] Z. Környei, S. Beke, T. Mihálffy, M. Jelitai, K.J. Kovács, Z. Szabó, B. Szabó, Cell sorting in a Petri dish controlled by computer vision, Sci. Rep. 3 (2013) 1088 https://doi.org/10.1038/srep01088.

[21] R. Salánki, T. Gerecsei, N. Orgovan, N. Sándor, B. Péter, Z. Bajtay, A. Erdei, R. Horvath, B. Szabó, Automated single cell sorting and deposition in submicroliter drops, Appl. Phys. Lett. 105 (2014). https://doi.org/10.1063/ 1.4893922, 083703.

[22] C. Brasko, K. Smith, C. Molnar, N. Farago, L. Hegedus, A. Balind, T. Balassa, A. Szkalisity, F. Sukosd, K. Kocsis, B. Balint, L. Paavolainen, M.Z. Enyedi, I. Nagy, L.G. Puskas, L. Haracska, G. Tamas, P. Horvath, Intelligent image- based in situ single-cell isolation, Nat. Commun. 9 (2018) 226. https:// doi.org/10.1038/s41467-017-02628-4.

[23] A. Manz, N. Graber, H.M. Widmer, Miniaturized total chemical analysis systems: a novel concept for chemical sensing, Sensor. Actuator. B Chem. 1 (1990) 244-248. https://doi.org/10.1016/0925-4005(90)80209-I.

[24] V. Lecault, A.K. White, A. Singhal, C.L. Hansen, Microfluidic single cell analysis: from promise to practice, Curr. Opin. Chem. Biol. 16 (2012) 381-390. https://doi.org/10.1016/j.cbpa.2012.03.022.

[25] F. Del Ben, M. Turetta, G. Celetti, A. Piruska, M. Bulfoni, D. Cesselli, W.T.S. Huck, G. Scoles, A method for detecting circulating tumor cells based on the measurement of single-cell metabolism in droplet-based microfluidics, Angew. Chem. Int. Ed. 55 (2016) 8581-8584. https://doi.org/ 10.1002/anie.201602328.

[26] K. Zhang, X. Han, Y. Li, S.Y. Li, Y. Zu, Z. Wang, L. Qin, Hand-held and integrated single-cell pipettes, J. Am. Chem. Soc. 136 (2014) 10858-10861. https:// doi.org/10.1021/ja5053279.

[27] D. Jin, B. Deng, J.X. Li, W. Cai, L. Tu, J. Chen, Q. Wu, W.H. Wang, A microfluidic device enabling high-efficiency single cell trapping, Biomicrofluidics 9 (2015). https://doi.org/10.1063/1.4905428, 014101.

[28] M. Junkin, S. Tay, Microfluidic single-cell analysis for systems immunology, Lab Chip 14 (2014) 1246-1260. https://doi.org/10.1039/C3LC51182K.

[29] S.M. Prakadan, A.K. Shalek, D.A. Weitz, Scaling by shrinking: empowering single-cell "omics" with microfluidic devices, Nat. Rev. Genet. 18 (2017) 345-361. https://doi.org/10.1038/nrg.2017.15.

[30] X. Wang, L. Yi, N. Mukhitov, A.M. Schrell, R. Dhumpa, M.G. Roper, Microfluidics-to-mass spectrometry: a review of coupling methods and applications, J. Chromatogr. A 1382 (2015) 98-116. https://doi.org/10.1016/ j.chroma.2014.10.039.

[31] J.C. McDonald, G.M. Whitesides, Poly(dimethylsiloxane) as a material for fabricating microfluidic devices, Acc. Chem. Res. 35 (2002) 491-499. https:// doi.org/10.1021/ar010110q.

[32] T. Xu, W. Yue, C.-W. Li, X. Yao, G. Cai, M. Yang, Real-time monitoring of suspension cell-cell communication using an integrated microfluidics, Lab Chip 10 (2010) 2271-2278. https://doi.org/10.1039/C004844E.

[33] R. Singhvi, A. Kumar, G.P. Lopez, G.N. Stephanopoulos, D.I. Wang, G.M. Whitesides, D.E. Ingber, Engineering cell shape and function, Science 264 (1994) 696-698. https://doi.org/10.1126/science.8171320.

[34] M. Chanasakulniyom, A. Glidle, J.M. Cooper, Cell proliferation and migration inside single cell arrays, Lab Chip 15 (2015) 208-215. https://doi.org/ 10.1039/C4LC00774C.

[35] F. Hillenkamp, J. Peter-Katalinic, MALDI MS: A Practical Guide to Instrumentation, Methods and Applications, John Wiley \& Sons, 2007.

[36] A. Amantonico, P.L. Urban, S.R. Fagerer, R.M. Balabin, R. Zenobi, Single-cell MALDI-MS as an analytical tool for studying intrapopulation metabolic heterogeneity of unicellular organisms, Anal. Chem. 82 (2010) 7394-7400. https://doi.org/10.1021/ac1015326.

[37] M. Aichler, A. Walch, MALDI imaging mass spectrometry: current frontiers and perspectives in pathology research and practice, Lab. Invest. 95 (2015) 422-431. https://doi.org/10.1038/labinvest.2014.156.

[38] M.A. Hossen, Y. Nagata, M. Waki, Y. Ide, S. Takei, H. Fukano, G.A. RomeroPerez, S. Tajima, I. Yao, K. Ohnishi, M. Setou, Decreased level of phosphatidylcholine (16:0/20:4) in multiple myeloma cells compared to plasma cells: a single-cell MALDI-IMS approach, Anal. Bioanal. Chem. 407 (2015) 5273-5280. https://doi.org/10.1007/s00216-015-8741-z.

[39] M.E. Dueñas, J.J. Essner, Y.J. Lee, 3D MALDI mass spectrometry imaging of a single cell: spatial mapping of lipids in the embryonic development of zebrafish, Sci. Rep. 7 (2017) 14946. https://doi.org/10.1038/s41598-01714949-x.

[40] T.-H. Ong, D.J. Kissick, E.T. Jansson, T.J. Comi, E.V. Romanova, S.S. Rubakhin, J.V. Sweedler, Classification of large cellular populations and discovery of rare cells using single cell matrix-assisted laser desorption/ionization timeof-flight mass spectrometry, Anal. Chem. 87 (2015) 7036-7042. https:// doi.org/10.1021/acs.analchem.5b01557.

[41] P.L. Urban, K. Jefimovs, A. Amantonico, S.R. Fagerer, T. Schmid, S. Mädler, J. Puigmarti-Luis, N. Goedecke, R. Zenobi, High-density micro-arrays for mass spectrometry, Lab Chip 10 (2010) 3206-3209. https://doi.org/10.1039/ COLC00211A.

[42] A.J. Ibáñez, S.R. Fagerer, A.M. Schmidt, P.L. Urban, K. Jefimovs, P. Geiger, R. Dechant, M. Heinemann, R. Zenobi, Mass spectrometry-based metabolomics of single yeast cells, Proc. Natl. Acad. Sci. U. S. A. 110 (2013) 8790-8794. https://doi.org/10.1073/pnas.1209302110.

[43] Y. Yang, Y. Huang, J. Wu, N. Liu, J. Deng, T. Luan, Single-cell analysis by ambient mass spectrometry, Trends Anal. Chem. 90 (2017) 14-26. https:// doi.org/10.1016/j.trac.2017.02.009.

[44] P. Wu, H.-M. Xiao, J. Ding, Q.-Y. Deng, F. Zheng, Y.-Q. Feng, Development of C60-based labeling reagents for the determination of low-molecular-weight compounds by matrix assisted laser desorption ionization mass (I): determination of amino acids in microliter biofluids, Anal. Chim. Acta 960 (2017) 90-100. https://doi.org/10.1016/j.aca.2017.01.018.

[45] W.-P. Peng, Y.-C. Yang, M.-W. Kang, Y.-K. Tzeng, Z. Nie, H.-C. Chang, W. Chang, C.-H. Chen, Laser-induced acoustic desorption mass spectrometry of single bioparticles, Angew. Chem. Int. Ed. Engl. 45 (2006) 1423-1426. https://doi.org/10.1002/anie.200503271.

[46] C. Xiong, X. Zhou, Q. He, X. Huang, J. Wang, W.-P. Peng, H.-C. Chang, Z. Nie, Development of visible-wavelength MALDI cell mass spectrometry for high- 
efficiency single-cell analysis, Anal. Chem. 88 (2016) 11913-11918. https:// doi.org/10.1021/acs.analchem.6b03789.

[47] Arundhoti Mandal, Singha Monisha, Addy Partha Sarathi, Basak Amit, Laser desorption ionization mass spectrometry: recent progress in matrix-free and label-assisted techniques, Mass Spectrom. Rev. 0 (2017). https://doi.org/ 10.1002/mas.21545.

[48] Bennett N. Walker, Trust Razunguzwa, Matthew Powell, Richard Knochenmuss, Akos Vertes, Nanophotonic ion production from silicon microcolumn arrays, Angew. Chem. Int. Ed. 48 (2009) 1669-1672. https://doi.org/10.1002/ anie.200805114.

[49] J.A. Stolee, B.N. Walker, V. Zorba, R.E. Russo, A. Vertes, Laser-nanostructure interactions for ion production, Phys. Chem. Chem. Phys. 14 (2012) 8453-8471. https://doi.org/10.1039/C2CP00038E.

[50] B.N. Walker, C. Antonakos, S.T. Retterer, A. Vertes, Metabolic differences in microbial cell populations revealed by nanophotonic ionization, Angew. Chem. Int. Ed. 52 (2013) 3650-3653. https://doi.org/10.1002/anie.201207348.

[51] A. Stopka Sylwia, Rong Charles, Andrew R. Korte, Sridevi Yadavilli, Javad Nazarian, Trust T. Razunguzwa, Nicholas J. Morris, Akos Vertes, Molecular imaging of biological samples on nanophotonic laser desorption ionization platforms, Angew. Chem. 128 (2016) 4558-4562. https://doi.org/ 10.1002/ange.201511691.

[52] P.J. O'Brien, M. Lee, M.E. Spilker, C.C. Zhang, Z. Yan, T.C. Nichols, W. Li, C.H. Johnson, G.J. Patti, G. Siuzdak, Monitoring metabolic responses to chemotherapy in single cells and tumors using nanostructure-initiator mass spectrometry (NIMS) imaging, Cancer Metab. 1 (2013) 4. https://doi.org/ 10.1186/2049-3002-1-4.

[53] J. Wang, Z. Wang, F. Liu, L. Cai, J. Pan, Z. Li, S. Zhang, H.-Y. Chen, X. Zhang, Y. Mo, Vacuum ultraviolet laser desorption/ionization mass spectrometry imaging of single cells with submicron craters, Anal. Chem. 90 (2018) 10009-10015. https://doi.org/10.1021/acs.analchem.8b02478.

[54] S. Datz, Condensed Matter: Applied Atomic Collision Physics, Academic Press, 2013.

[55] M.K. Passarelli, C.F. Newman, P.S. Marshall, A. West, I.S. Gilmore, J. Bunch, M.R. Alexander, C.T. Dollery, Single-cell analysis: visualizing pharmaceutical and metabolite uptake in cells with label-free 3D mass spectrometry imaging, Anal. Chem. 87 (2015) 6696-6702. https://doi.org/10.1021/acs.analchem.5b00842.

[56] L. Huang, Y. Chen, L.-T. Weng, M. Leung, X. Xing, Z. Fan, H. Wu, Fast singlecell patterning for study of drug-induced phenotypic alterations of HeLa cells using time-of-flight secondary ion mass spectrometry, Anal. Chem. 88 (2016) 12196-12203. https://doi.org/10.1021/acs.analchem.6b03170.

[57] D.J. Graham, J.T. Wilson, J.J. Lai, P.S. Stayton, D.G. Castner, Three-dimensional localization of polymer nanoparticles in cells using ToF-SIMS, Biointerphases 11 (2015). https://doi.org/10.1116/1.4934795, 02A304.

[58] M.L. Kraft, H.A. Klitzing, Imaging lipids with secondary ion mass spectrometry, Biochim. Biophys. Acta Mol. Cell Biol. Lipids 1841 (2014) 1108-1119. https://doi.org/10.1016/j.bbalip.2014.03.003.

[59] G.L. Fisher, A.L. Bruinen, N. Ogrinc Potočnik, J.S. Hammond, S.R. Bryan, P.E. Larson, R.M.A. Heeren, A new method and mass spectrometer design for TOF-SIMS parallel imaging MS/MS, Anal. Chem. 88 (2016) 6433-6440. https://doi.org/10.1021/acs.analchem.6b01022.

[60] M.K. Passarelli, A. Pirkl, R. Moellers, D. Grinfeld, F. Kollmer, R. Havelund, C.F. Newman, P.S. Marshall, H. Arlinghaus, M.R. Alexander, A. West, S. Horning, E. Niehuis, A. Makarov, C.T. Dollery, I.S. Gilmore, The 3D OrbiSIMS-label-free metabolic imaging with subcellular lateral resolution and high mass-resolving power, Nat. Methods 14 (2017) 1175-1183. https:// doi.org/10.1038/nmeth.4504.

[61] Z. Lei, D.V. Huhman, L.W. Sumner, Mass spectrometry strategies in metabolomics, J. Biol. Chem. 286 (2011) 25435-25442. https://doi.org/10.1074/ jbc.R111.238691.

[62] H. Mizuno, N. Tsuyama, T. Harada, T. Masujima, Live single-cell video-mass spectrometry for cellular and subcellular molecular detection and cell classification, J. Mass Spectrom. 43 (2008) 1692-1700. https://doi.org/10.1002/ jms.1460.

[63] Y. Fukano, N. Tsuyama, H. Mizuno, S. Date, M. Takano, T. Masujima, Drug metabolite heterogeneity in cultured single cells profiled by pico-trapping direct mass spectrometry, Nanomedicine 7 (2012) 1365-1374. https:// doi.org/10.2217/nnm.12.34.

[64] K. Yamamoto, K. Takahashi, H. Mizuno, A. Anegawa, K. Ishizaki, H. Fukaki, M. Ohnishi, M. Yamazaki, T. Masujima, T. Mimura, Cell-specific localization of alkaloids in Catharanthus roseus stem tissue measured with Imaging MS and single-cell MS, Proc. Natl. Acad. Sci. U. S. A. 113 (2016) 3891-3896. https:// doi.org/10.1073/pnas.1521959113.

[65] N. Pan, W. Rao, N.R. Kothapalli, R. Liu, A.W.G. Burgett, Z. Yang, The singleprobe: a miniaturized multifunctional device for single cell mass spectrometry analysis, Anal. Chem. 86 (2014) 9376-9380. https://doi.org/ $10.1021 /$ ac5029038.

[66] N. Pan, W. Rao, S.J. Standke, Z. Yang, Using dicationic ion-pairing compounds to enhance the single cell mass spectrometry analysis using the singleprobe: a microscale sampling and ionization device, Anal. Chem. 88 (2016) 6812-6819. https://doi.org/10.1021/acs.analchem.6b01284.

[67] M. Sun, Z. Yang, B. Wawrik, Metabolomic fingerprints of individual algal cells using the single-probe mass spectrometry technique, Front. Plant Sci. 9 (2018). https://doi.org/10.3389/fpls.2018.00571.

[68] R. Liu, N. Pan, Y. Zhu, Z. Yang, T-Probe, An integrated microscale device for online in situ single cell analysis and metabolic profiling using mass spectrometry, Anal. Chem. 90 (2018) 11078-11085. https://doi.org/10.1021/ acs.analchem.8b02927.

[69] L. Zhang, A. Vertes, Energy charge, redox state, and metabolite turnover in single human hepatocytes revealed by capillary microsampling mass spectrometry, Anal. Chem. 87 (2015) 10397-10405. https://doi.org/10.1021/ acs.analchem.5b02502.

[70] L. Zhang, A. Vertes, Single-cell mass spectrometry approaches to explore cellular heterogeneity, Angew. Chem. Int. Ed. (2018). https://doi.org/ 10.1002/anie.201709719.

[71] H. Zhu, G. Zou, N. Wang, M. Zhuang, W. Xiong, G. Huang, Single-neuron identification of chemical constituents, physiological changes, and metabolism using mass spectrometry, Proc. Natl. Acad. Sci. U. S. A. 114 (2017) 2586-2591. https://doi.org/10.1073/pnas.1615557114.

[72] R.V. Kapoore, S. Vaidyanathan, Towards quantitative mass spectrometrybased metabolomics in microbial and mammalian systems, Philos. Trans. A Math. Phys. Eng. Sci. 374 (2016). https://doi.org/10.1098/rsta.2015.0363.

[73] R. Yin, V. Prabhakaran, J. Laskin, Quantitative extraction and mass spectrometry analysis at a single-cell level, Anal. Chem. 90 (2018) 7937-7945. https://doi.org/10.1021/acs.analchem.8b00551.

[74] R. Ramautar, G.W. Somsen, G.J. Jong, CE-MS for metabolomics: developments and applications in the period 2014-2016, Electrophoresis 38 (2017) 190-202. https://doi.org/10.1002/elps.201600370.

[75] R.M. Onjiko, S.A. Moody, P. Nemes, Single-cell mass spectrometry reveals small molecules that affect cell fates in the 16-cell embryo, Proc. Natl. Acad. Sci. U. S. A. 112 (2015) 6545-6550. https://doi.org/10.1073/pnas.1423682112.

[76] J.T. Aerts, K.R. Louis, S.R. Crandall, G. Govindaiah, C.L. Cox, J.V. Sweedler, Patch clamp electrophysiology and capillary electrophoresis-mass spectrometry metabolomics for single cell characterization, Anal. Chem. 86 (2014) 3203-3208. https://doi.org/10.1021/ac500168d.

[77] R.M. Onjiko, D.O. Plotnick, S.A. Moody, P. Nemes, Metabolic comparison of dorsal versus ventral cells directly in the live 8-cell frog embryo by microprobe single-cell CE-ESI-MS, Anal. Methods 9 (2017) 4964-4970. https:/| doi.org/10.1039/C7AY00834A.

[78] Ramautar Rawi, W. Somsen Govert, J. de Jong Gerhardus, CE-MS for metabolomics: developments and applications in the period 2012-2014, Electrophoresis 36 (2015) 212-224. https://doi.org/10.1002/elps.201400388.

[79] X. Guo, T.L. Fillmore, Y. Gao, K. Tang, Capillary electrophoresis-nanoelectrospray ionization-selected reaction monitoring mass spectrometry via a true sheathless metal-coated emitter interface for robust and high-sensitivity sample quantification, Anal. Chem. 88 (2016) 4418-4425. https://doi.org/10.1021/ acs.analchem.5b04912.

[80] T.J. Comi, M.A. Makurath, M.C. Philip, S.S. Rubakhin, J.V. Sweedler MALDI MS guided liquid microjunction extraction for capillary electrophoresis-electrospray ionization MS analysis of single pancreatic islet cells, Anal. Chem. 89 (2017) 7765-7772. https://doi.org/10.1021/acs. analchem.7b01782.

[81] N.L. Kuehnbaum, P. Britz-McKibbin, New advances in separation science for metabolomics: resolving chemical diversity in a post-genomic era, Chem Rev. 113 (2013) 2437-2468. https://doi.org/10.1021/cr300484s.

[82] J.P. Junker, A. van Oudenaarden, Every cell is special: genome-wide studies add a new dimension to single-cell biology, Cell 157 (2014) 8-11. https:// doi.org/10.1016/j.cell.2014.02.010.

[83] H. Li, E.T. Courtois, D. Sengupta, Y. Tan, K.H. Chen, J.J.L. Goh, S.L. Kong, C. Chua, L.K. Hon, W.S. Tan, M. Wong, P.J. Choi, L.J.K. Wee, A.M. Hillmer, I.B. Tan, P. Robson, S. Prabhakar, Reference component analysis of single-cell transcriptomes elucidates cellular heterogeneity in human colorectal tumors, Nat. Genet. 49 (2017) 708-718. https://doi.org/10.1038/ng.3818.

[84] T.F. Jorge, J.A. Rodrigues, C. Caldana, R. Schmidt, J.T. van Dongen, J. ThomasOates, C. António, Mass spectrometry-based plant metabolomics: metabolite responses to abiotic stress, Mass Spectrom. Rev. 35 (2016) 620-649. https:// doi.org/10.1002/mas.21449.

[85] S.R. Fagerer, T. Schmid, A.J. Ibáñez, M. Pabst, R. Steinhoff, K. Jefimovs, P.L. Urban, R. Zenobi, Analysis of single algal cells by combining mass spectrometry with Raman and fluorescence mapping, Analyst 138 (2013) 6732-6736. https://doi.org/10.1039/c3an01135f.

[86] M. Lorenzo Tejedor, H. Mizuno, N. Tsuyama, T. Harada, T. Masujima, In situ molecular analysis of plant tissues by live single-cell mass spectrometry, Anal. Chem. 84 (2012) 5221-5228. https://doi.org/10.1021/ac202447t.

[87] D. Wang, S. Bodovitz, Single cell analysis: the new frontier in 'omics', Trends Biotechnol. 28 (2010) 281-290. https://doi.org/10.1016/j.tibtech.2010.03.002.

[88] P. Nemes, A.M. Knolhoff, S.S. Rubakhin, J.V. Sweedler, Metabolic differentiation of neuronal phenotypes by single-cell capillary electrophoresis-electrospray ionization-mass spectrometry, Anal. Chem. 83 (2011) 6810-6817. https:// doi.org/10.1021/ac2015855.

[89] H. Zhu, N. Wang, L. Yao, Q. Chen, R. Zhang, J. Qian, Y. Hou, W. Guo, S. Fan, S. Liu, Q. Zhao, F. Du, X. Zuo, Y. Guo, Y. Xu, J. Li, T. Xue, K. Zhong, X. Song, G. Huang, W. Xiong, Moderate UV exposure enhances learning and memory by promoting a novel glutamate biosynthetic pathway in the brain, Cell 173 (2018) 1716-1727. https://doi.org/10.1016/j.cell.2018.04.014. e17.

[90] M.E. Bunnage, E.L.P. Chekler, L.H. Jones, Target validation using chemical probes, Nat. Chem. Biol. (2013). https://doi.org/10.1038/nchembio.1197.

[91] C. Vinegoni, J.M. Dubach, G.M. Thurber, M.A. Miller, R. Mazitschek, R. Weissleder, Advances in measuring single-cell pharmacokinetics and pharmacology in vivo, Drug Discov. Today 20 (2015) 1087-1092. https:// doi.org/10.1016/j.drudis.2015.05.011. 
[92] B. Gold, M. Cankovic, L.V. Furtado, F. Meier, C.D. Gocke, Do circulating tumor cells, exosomes, and circulating tumor nucleic acids have clinical utility? A report of the association for molecular pathology, J. Mol. Diagn. 17 (2015) 209-224. https://doi.org/10.1016/j.jmoldx.2015.02.001.

[93] X.-C. Zhang, Q. Zang, H. Zhao, X. Ma, X. Pan, J. Feng, S. Zhang, R. Zhang, Z. Abliz, X. Zhang, Combination of droplet extraction and pico-ESI-MS allows the identification of metabolites from single cancer cells, Anal. Chem. 90 (2018) 9897-9903. https://doi.org/10.1021/acs.analchem.8b02098.

[94] X.-C. Zhang, Z.-W. Wei, X.-Y. Gong, X.-Y. Si, Y.-Y. Zhao, C.-D. Yang, S. C. Zhang, X.-R. Zhang, Integrated droplet-based microextraction with ESI-MS for removal of matrix interference in single-cell analysis, Sci. Rep. 6 (2016) 24730. https://doi.org/10.1038/srep24730.

[95] Z. Wei, X. Xiong, C. Guo, X. Si, Y. Zhao, M. He, C. Yang, W. Xu, F. Tang, X. Fang, S. Zhang, X. Zhang, Pulsed direct current electrospray: enabling systematic analysis of small volume sample by boosting sample economy, Anal. Chem. 87 (2015) 11242-11248. https://doi.org/10.1021/acs.analchem.5b02115.

[96] K. Haug, R.M. Salek, P. Conesa, J. Hastings, P. de Matos, M. Rijnbeek, T. Mahendraker, M. Williams, S. Neumann, P. Rocca-Serra, E. Maguire, A. González-Beltrán, S.-A. Sansone, J.L. Griffin, C. Steinbeck, MetaboLights an open-access general-purpose repository for metabolomics studies and associated meta-data, Nucleic Acids Res. 41 (2013) D781-D786. https:// doi.org/10.1093/nar/gks1004.

[97] M. Sud, E. Fahy, D. Cotter, K. Azam, I. Vadivelu, C. Burant, A. Edison, O. Fiehn, R. Higashi, K.S. Nair, S. Sumner, S. Subramaniam, Metabolomics Workbench: an international repository for metabolomics data and metadata, metabolite standards, protocols, tutorials and training, and analysis tools, Nucleic Acids Res. 44 (2016) D463-D470. https://doi.org/10.1093/nar/gkv1042.

[98] R. Goodacre, D. Broadhurst, A.K. Smilde, B.S. Kristal, J.D. Baker, R. Beger C. Bessant, S. Connor, G. Capuani, A. Craig, T. Ebbels, D.B. Kell, C. Manetti, J. Newton, G. Paternostro, R. Somorjai, M. Sjöström, J. Trygg, F. Wulfert, Proposed minimum reporting standards for data analysis in metabolomics, Metabolomics 3 (2007) 231-241. https://doi.org/10.1007/s11306-007-0081-3.
[99] R.A. Spicer, R. Salek, C. Steinbeck, Compliance with minimum information guidelines in public metabolomics repositories, Sci. Data 4 (2017) 170137. https://doi.org/10.1038/sdata.2017.137.

[100] I. Aretz, D. Meierhofer, Advantages and pitfalls of mass spectrometry based metabolome profiling in systems biology, Int. J. Mol. Sci. 17 (2016). https:// doi.org/10.3390/ijms17050632.

[101] R. Spicer, R.M. Salek, P. Moreno, D. Cañueto, C. Steinbeck, Navigating freelyavailable software tools for metabolomics analysis, Metabolomics 13 (2017). https://doi.org/10.1007/s11306-017-1242-7.

[102] R.L. Davidson, R.J.M. Weber, H. Liu, A. Sharma-Oates, M.R. Viant, Galaxy-M: a galaxy workflow for processing and analyzing direct infusion and liquid chromatography mass spectrometry-based metabolomics data, GigaScience 5 (2016) 10. https://doi.org/10.1186/s13742-016-0115-8.

[103] R. Tautenhahn, G.J. Patti, D. Rinehart, G. Siuzdak, XCMS online: a web-based platform to process untargeted metabolomic data, Anal. Chem. 84 (2012) 5035-5039. https://doi.org/10.1021/ac300698c.

[104] S. Gibb, K. Strimmer, MALDIquant: a versatile R package for the analysis of mass spectrometry data, Bioinformatics 28 (2012) 2270-2271. https:// doi.org/10.1093/bioinformatics/bts447.

[105] F. Giacomoni, G. Le Corguillé, M. Monsoor, M. Landi, P. Pericard, M. Pétéra, C. Duperier, M. Tremblay-Franco, J.-F. Martin, D. Jacob, S. Goulitquer, E.A. Thévenot, C. Caron, Workflow4Metabolomics: a collaborative research infrastructure for computational metabolomics, Bioinformatics 31 (2015) 1493-1495. https://doi.org/10.1093/bioinformatics/btu813.

[106] J. Xia, I.V. Sinelnikov, B. Han, D.S. Wishart, MetaboAnalyst 3.0 - making metabolomics more meaningful, Nucleic Acids Res. 43 (2015) W251-W257. https://doi.org/10.1093/nar/gkv380.

[107] F. Fernández-Albert, R. Llorach, C. Andrés-Lacueva, A. Perera, An R package to analyse LC/MS metabolomic data: MAIT (Metabolite Automatic Identification Toolkit), Bioinformatics 30 (2014) 1937-1939. https://doi.org/10.1093/bioinformatics/btu136. 